\title{
Odor intensity after self-adaptation and cross-adaptation'
}

\author{
JOHN B. PIERCE FOUNDA TION LABORATORY AND SCHOOL OF MEDICINE, YALE UNIVERSITY
}

Psychophysical functions for the odor intensity of n-propanol and n-pentanol were obtained after no adaptation and after self-adaptation and cross-adaptation. Adaptation caused the psychophysical function to become steeper and generally concave downward in log-log coordinates. Increases in the intensity of a self-adapting stimulus produced relatively greater increases in the steepness of the functions than did increases in adapting duration. $A$ comparison between the odorants revealed that propanol and pentanol have equal self-adapting effects when their respective adapting concentrations are matched for subjective intensity. Cross-adaptation had approximately the same effect as self-adaptation on the form of the psychophysical function, but a cross-adapting stimulus of a specified subjective intensity was less effective than a self-adapting stimulus of the same intensity. Adaptation to pentanol caused a larger reduction in the perceived intensity of propanol than adaptation to propanol caused in the perceived intensity of pentanol.

Investigations of olfactory adaptation have been concerned almost exclusively with two problems: the effects of adaptation on the olfactory threshold (Moncrieff, 1956, 1957; Cheesman \& Mayne, 1953; Cheesman \& Townsend, 1956; Stuiver, 1958) and the effects of continuous exposure on the apparent intensity of an odor (Woodrow \& Karpman, 1917; Schutz, Overbeck, \& Laymon, 1958; Stuiver, 1958; Ekman, Berglund, Berglund, \& Lindvall, 1967). The present investigation extends the study of olfactory adaptation to the problem of how adaptation to a given odorous substance affects the perceived magnitude of the sume substance (self-adaptation) and other substances (cross-adaptation) having concentrations that span large segments of the dynamic range of intensity. In other words, how do various conditions of self-adaptation and cross-adaptation influence the form of the psychophysical function for odor?

\section{EXPERIMENT 1: SELF-ADAPTATION}

An important question to ask in an investigation of self-adaptation is, "When do two different adapting stimuli exert equivalent adapting effects?" For example, can a weak odor smelled for a long duration have the same adapting effect as a strong odor smelled for a short duration? It is pertinent that this question cannot be answered satisfactorily by a knowledge of how adaptation affects the absolute threshold, because two adapting conditions that exert an equivalent effect on the olfactory threshold may exert quite unequal effects on suprathreshold intensities. Within this context, Experiment 1 investigates how changes in both adapting intensity and duration affect the psychophysical functions for two different od orants, n-propanol and n-pentanol. It therefore allows an examination of self-adaptation across odorants, as well as within the same odorant. Furthermore, it permits a test of the hypothesis that two different odorants will have equal self-adapting effectiveness when their respective adapting concentrations are matched for subjective intensity.

\section{Method}

Observers. Nineteen undergraduates were paid $\$ 1.50$ per session to serve as Os.

Apparatus and materials. The apparatus used to control and deliver the stimuli was a two-channel, air-dilution olfactometer. One channel controlled the adapting concentrations and the other the test concentrations (cf. Cain, 1969, for a schematic of one channel). Desired concentrations were obtained by mixing dry, odorless air in various proportions to air saturated with the odorant. Saturation was accomplished by sparging the air in one line through $400 \mathrm{ml}$ of the odorant distributed into three gas-washing bottles. Repeated tests of the weight lost from the odorants when known volumes of air were sparged through the washing bottles confirmed that saturation was complete.

Materials used to construct the device were normally odorless and easily cleaned. Odorous air in the system came into contact predominantly with Teflon and glass, and with small amounts of polypropylene and brass.

The experiment was conducted in an air-conditioned room with a temperature of $70 \pm 1 \operatorname{deg} F$ and a relative humidity of $50 \%$ to $60 \%$. The test chamber was a Formica-lined booth with a large glass window in the front wall and exhaust fans on the top and on one side. Two stimulus delivery tubes, 6 in. apart, protruded from the front wall at an angle of 45 deg to a position just in front of the $O$. A series of relays and timers controlled the time a stimulus was available at each delivery tube and the time between trials. For conditions that required more than one inhalation on a trial, a metronome paced the breathing rate of the $O$ at $30 \mathrm{cpm}$.

N-propanol $\left(C_{3}\right)$ and n-pentanol $\left(C_{5}\right)$ were used as odorants, and overall flow rate was fixed at 4 liters/minute for propanol and 6 liters/minute for pentanol. Concentration series for each ranged from $100 \%$ to $1.59 \%$ of the saturated vapor in six equal logarithmic steps.

Procedure. The experiment was designed to obtain nine psychophysical functions for each of the two odorants; one function under nonadaptation and eight under various conditions of adaptation. Accordingly, each $O$ served in 18 experimental sessions.

In each session the Os made magnitude estimations of intensity of the seven test concentrations of propanol or pentanol. They were instructed to assign to the first stimulus presented (the middle concentration of the series) any number they deemed appropriate, and to let their judgments of subsequent concentrations reflect the ratio relations among perceived intensities. In the nonadaptation conditions, each of the seven concentrations of the odorant was then presented twice in an irregular order. Each stimulus was available for $3.5 \mathrm{sec}$ on a trial, and the $O$ was allowed one inhalation for each exposure. There was a 1 -min interval between trials. In both of these sessions, the $O s$ also judged a single concentration of ethyl acetate, so that later the intercepts of the two psychophysical functions could be meaningfully related to each other.

In the adaptation conditions, presentations of the test concentrations were preceded by an adapting stimulus. Within a session, the adapting stimulus was constant in both concentration and duration. The concentrations of the adapting stimuli were chosen on the basis of a previous scaling experiment (cf. Cain, 1969; Experiment 5). There were three levels of adapting intensity, and within each level the adapting stimuli for propanol and pentanol were matched for subjective intensity. Table 1 summarizes the adapting 
Table 1

Self-Adaptation Conditions for Propanol $\left(C_{3}\right)$ and Pentanol (Cs)

\begin{tabular}{|c|c|c|c|}
\hline \multirow{2}{*}{$\begin{array}{l}\text { Adapting } \\
\text { Intensity } \\
\text { (Relative) }\end{array}$} & \multicolumn{2}{|c|}{$\begin{array}{c}\text { Matched } \\
\text { Concentrations } \\
\text { (mg/L) }\end{array}$} & \multirow{2}{*}{$\begin{array}{c}\text { Exposure } \\
\text { (No. of Breaths) }\end{array}$} \\
\hline & $C_{3}$ & $C_{5}$ & \\
\hline $\begin{array}{l}\text { Low } \\
\text { Low } \\
\text { Middle } \\
\text { Middle } \\
\text { Middle } \\
\text { Middle } \\
\text { Middle } \\
\text { High }\end{array}$ & $\begin{array}{r}2.0 \\
2.0 \\
6.3 \\
6.3 \\
6.3 \\
6.3 \\
6.3 \\
21.6\end{array}$ & $\begin{array}{l}0.5 \\
0.5 \\
2.1 \\
2.1 \\
2.1 \\
2.1 \\
2.1 \\
9.2\end{array}$ & $\begin{array}{c}3 \\
8 \\
3 \\
5 \\
8 \\
8 \text { plus } 3 \text { recovery } \\
15 \\
3\end{array}$ \\
\hline
\end{tabular}

conditions in terms of the intensity (concentration) and duration (number of breaths) of the adapting stimuli. The ratio of subjective intensity between adjacent adapting levels was 2.25 , and there was therefore a 5-to-1 subjective ratio between the high and low adapting levels. The durations of the adapting stimuli were chosen to cover a range that could be comfortably handled in a scaling experiment, 3 to 15 breaths, also a 5-to-1 ratio.

In the beginning of each adaptation session, the $O$ smelled the middle concentration of the series without prior exposure to the adapting stimulus. Thereafter, he made the required number of inhalations from the adapting channel before he inhaled any of the test concentrations. In one condition (recovery), he made three inhalations of pure air between the presentations of the adapting stimulus and each test concentration. In all other conditions, he inhaled the test concentrations on the inhalation that followed the final inhalation of the adapting stimulus.

For seven of the eight adapting conditions, the test concentrations were presented twice in a session, and the interval between trials was $1.5 \mathrm{~min}$. For the 15-breath exposure to the adapting stimulus of middle intensity, the test concentrations were presented once, and the interval between trials was $2.5 \mathrm{~min}$. The order of presentation of the test concentrations was irregular and different for each session.

Fig. 1. Psychophysical functions for propanol $\left(C_{3}\right)$ and pentanol $\left(C_{5}\right)$ obtained under nonadaptation and under three levels of adaptation. The duration of each adapting stimulus was three breaths. (For clarity in this and in subsequent figures, only one median magnitude estimation of zero is shown for each condition. The points depicted at ordinate values of zero imply that the median also equaled zero at all lower test concentrations.)

\section{Results}

Each O's data were transformed to a modulus of 10 before the group data were analyzed. If an $O$ used a modulus of $\mathbf{5 0}$ (i.e., assigned 50 to the stimulus that was presented first in each session, $12.5 \%$ saturation), all of his estimates for that session were multiplied by 0.2 . If he used a modulus of 1.0 , his estimates were multiplied by 10 , etc. In the conditions where two estimates were required for each concentration, the geometric mean of these two estimates was computed. The median was then used to summarize the data across Os. This measure of central tendency was used primarily because of the large number of zero responses obtained in the adaptation conditions. (One $\mathrm{O}$ produced very erratic adaptation data and his results were therefore not counted.)

Previous experiments (Engen, Cain, \& Rovee, 1968; Cain, 1969) showed that, under normal (i.e., nonadaptation) conditions, the size of the exponent of the psychophysical function for aliphatic alcohols decreases as a function of carbon chain-length. In the present experiment, the exponent for propanol $\left(C_{3}\right)$ was 0.74 and the exponent for pentanol $\left(\mathrm{C}_{5}\right)$ was 0.58 (Fig. 1).

Adapting intensity. Figure 1 shows that adaptation produced a profound change in the dynamic relation between subjective intensity and physical concentration. The functions obtained under adaptation are concave downward and much steeper than the normal psychophysical functions. Each increase in adapting intensity produced a sizable increase in the steepness of the functions. This sharp increase in rate of growth shows that the adapting stimulus greatly reduces the perceived intensity of low test concentrations but leaves high concentrations relatively unaffected. Except for the high-intensity condition for pentanol, where the concentration of the adapting stimulus equaled the concentration of the highest test stimulus, the effects of adaptation were reduced to zero at the highest test stimuli.

Adapting duration. Figures 2 and 3 show that adapting duration (number of breaths) had a surprisingly small effect on the functions. For low-intensity adaptation (Fig. 2), the increase from three to eight breaths of exposure had a relatively minor but noticeable effect. The same was true for middle-intensity adaptation with $\mathrm{C}_{3}$ (Fig. 3).

The results for $C_{5}$ were not so clear, but variability in the data could have concealed a small effect of adapting duration. Thus, a 5-to-1 change in adapting time was not nearly so important as a 5-to-1 change in adapting intensity. As Fig. 4 shows, however, a recovery period of only three breaths sizably reduced the effects of adaptation.

Comparison between $C_{3}$ and $C_{5}$. In order to compare directly the psychophysical functions for $\mathrm{C}_{3}$ to those for $C_{5}$, the medians of the normalized magnitude estimates for $C_{3}$ were multiplied by 1.1 and the medians for $\mathrm{C}_{5}$ by 0.9 . This "intercept transformation" was dictated by the magnitude estimates assigned to the solution of ethyl acetate and simply shifted the two sets of functions along the ordinate to a position where a magnitude estimate of 20 , for example, reflected equal subjective intensity for both odorants. With this adjustment, it was then possible to compare graphically the adapting effectiveness of $C_{3}$ and $C_{5}$ (Fig. 5).

Figure 5 shows that for each of the eight conditions of adaptation, the psychophysical functions for the two odorants are practically the same. Not only do their shapes coincide, but for each adaptation condition the two functions fall almost exactly on top of one another. These results strongly support the hypothesis that concentrations of propanol and pentanol that match in subjective

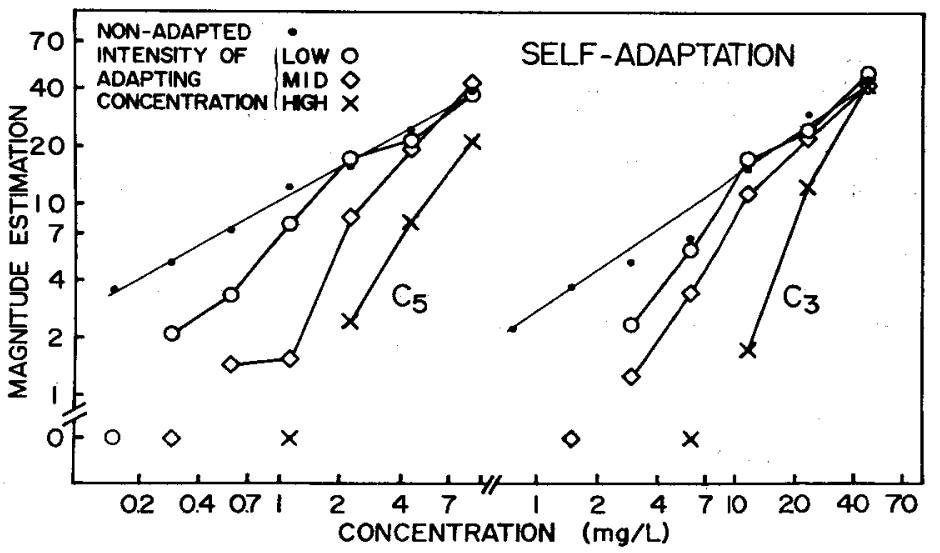




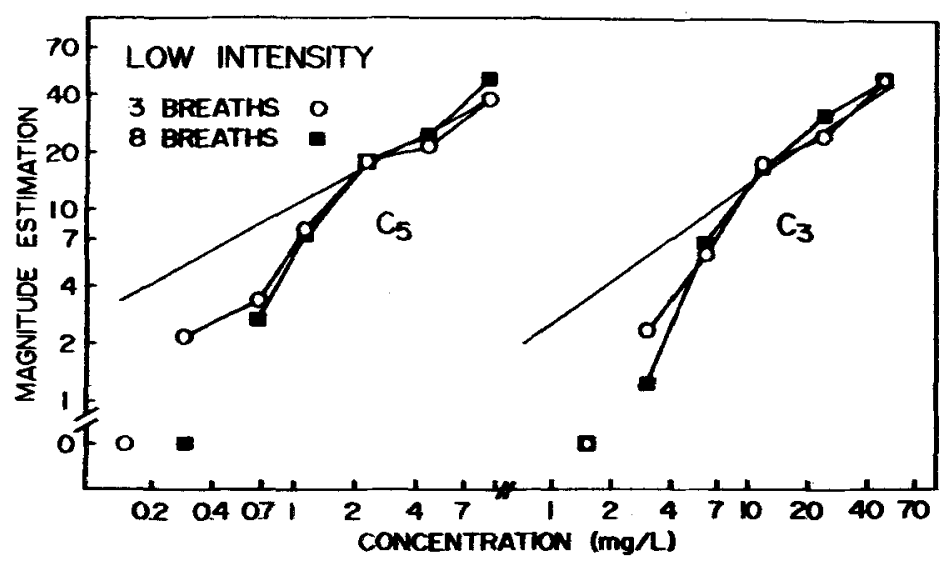

intensity have equal self-adapting effectiveness.

\section{EXPERIMIENT 2:}

\section{CMOSS-ADAPTATION}

Self-edaptation and cross-aiaptation are typically thought to be two axpects of the same phenomenon. Although both types of adaptation raise the olfactory threshold, it is not clear that their effects are similar on suprathreshold odor intensities. In fact, Schutz, Overbeck, and Laymon (1958; cf. also Schutz \& Laymon, 1959) conchuded that cross-adaptation does not significantly affect the perceived intensity of suprathrehold test stimuli. However, Schutz et al did not vary the concentrations of their test stimuli and, in fact, their test stimuli appear to have been about as strong as their cross-adapting stimuli. Had test stimuli of lower suprathreshold concentrations been used, the effects of cross-adaptation might have become evident.

In light of this evidence, it seems important to compare the effects of cross-adaptation to the effects of self-adaptation over a large segment of the dymanic range and to adk whether or not both types of adaptation have the same effect on the form of the poychophysical intensity.

\section{Method} Experiment 1. condition, they took three breaths.

Resalts function. Another question of interest is whether or not pentanol and propanol will cross-adapt each other to an equivalent degree when the cross-adapting concentrations are matched for subjective

Obsewers Nineteen Os were paid $\mathbf{5 1 . 5 0}$ per session. Ten had served in

Procedure. The procedure was the same as that of Experiment 1. Those Os who had not participated in Experiment 1 judged the concentration series of propanol and pentanol under normal conditions, and then all of the Os served in six conditions of cross-adaptation. Propanol was the cross-adapting stimulus in three of the conditions and pentanol in the other three. The adapting concentrations were the same as those used in Experiment 1 and were, therefore, considered to be matched for subjective magnitude at each of the three levels of adapting intensity (low, middle, and high). In the low- and middle-intensity conditions, the Os took eight breaths of the adapting stimulus; in the high-intensity

The exponent of the normal

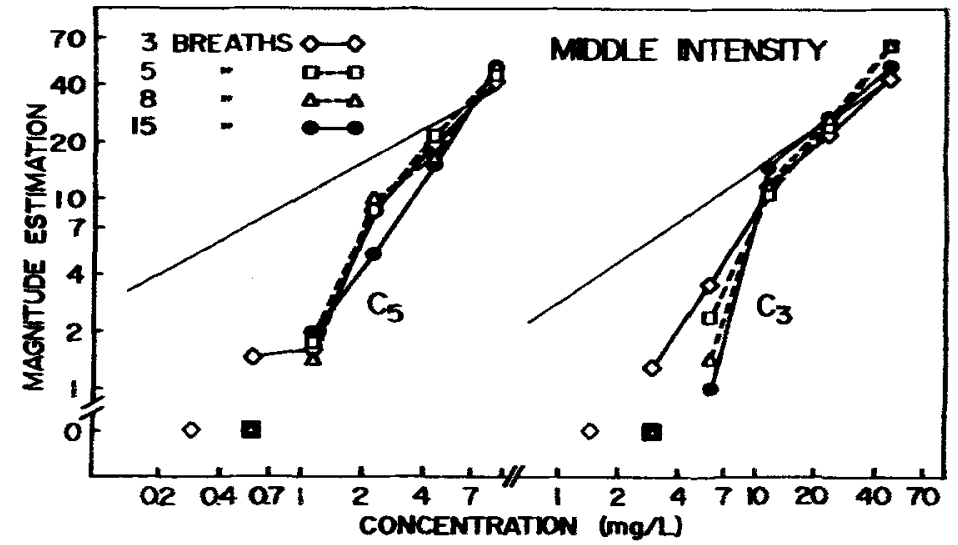

Fi. 2. Low-inteneity adptation for exposares of three breath and aint breathe The traint lives, proviled for reference, represent the normal poychophyicel funetions.

psychophysical function for pentanol componted for the $19 \mathrm{O}^{3}$ in the present experiment tumed out to be 0.43 , compared with a value of 0.58 in Experiment 1. On the other hand, the exponent of the normal function for propenal was 0.74 in both experiments.

Both propanol and pentanol were effective as crowadapting stimuli (Fig-6). Propenol, however, had a much smaller effect than pentand. In fact, for the low-intensity condition, propancl had no effect on the poychophysical function for pentanal, and for the bigh-intensity condition it was less effective than the low-intensity condition of self-adeptation (Experiment 1). The middle-intensity condition shows quite cleany that a croso-adapting stimulus con have littie or no effect on one test concentration but a lange effect on a sightly lower test concentration.

The cross-adapting effect of pentanol on propand was quite marked. As Fig-7 shows, the middle- and high-intensity cross-adapting stimuli were ahmost as effective as the middle- and high-intensity self-adapting stimuli from Experiment 1. It is also apparent that cross-adaptation has approximately the zame effect as self-adaptation on the shape of the nomal psychophysical function.

\section{DSCUSTron}

Propand and pentanol are structurally and chemically similar. Nevertheless, in several respects their poychophysical properties are quite different. The threhold concentration for pentanol is lower than that for propanol (Wright, 1964), the exponent of the psychophysical power function is lower for pentanol than for propanol, and the two substances display unequal degrees of croseradaptation on each other (Experiment 2). Despite these pisychophysical differences, their ability to act as self-adapters appears to be virtually identical if one measures their intenrity, not in terms of physical concentration, but in terms of subjective intenarty. Figure 5 makes it quite clear that subjectively equated concentrations of propanol and pentanol have equal self-admpting effects. Will this result generalize to pairs of odorants that are chemically discimilar? If not, it will

Fic 3. Middleintencity odeptation for exposmes from 3 to 15 breathe. 


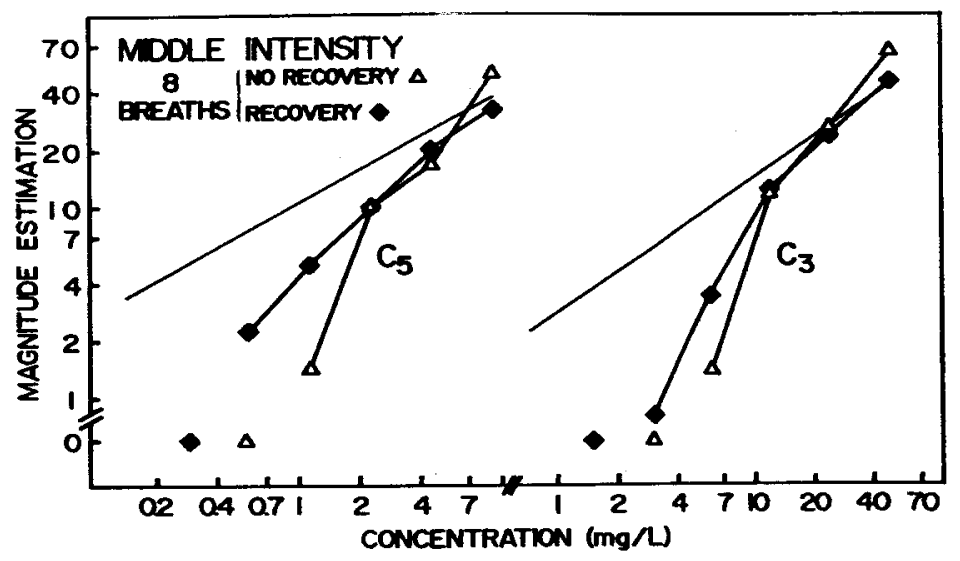

Fig. 4. Middle-intensity adaptation for exposures of eight breaths with no recovery and with a recovery period of three breaths.

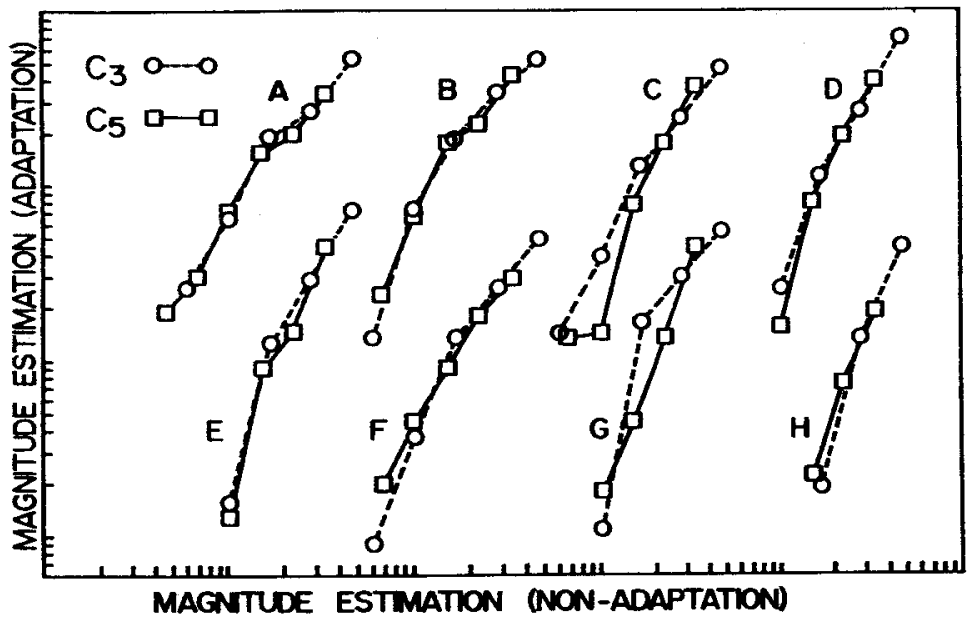

Fig. 5. Magnitude estimation under each of the eight conditions of adaptation as a function of magnitude estimation under normal (nonadaptation) conditions. The coordinates are relative and the vahes of zero included in the previous figures have been excluded for charity. The conditions are designated as follows: (A) low intensity, 3 breaths; (B) low intensity, 8 breaths; (C) middle intensity, 3 breaths; (D) middle intensity, 5 breaths; (E) middle intensity, 8 breaths; (F) middle intensity, recovery; (G) middle intensity, 15 breaths; (H) high intensity, 3 breaths.

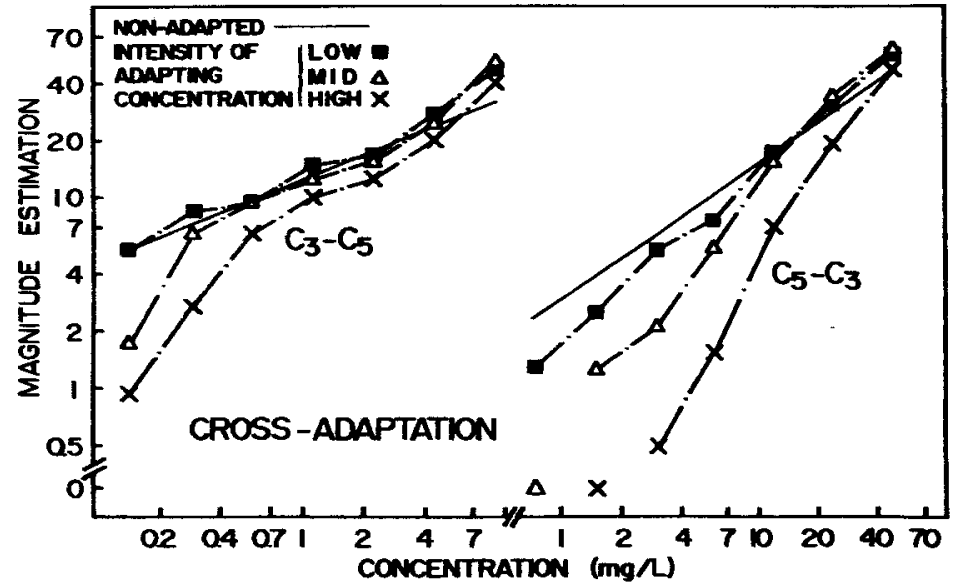

Fis 6. Psychophysical functions obtained under three levels of cross-adaptation. The straight lines, provided for reference, represent the psychophysical functions obtained under normal conditions.

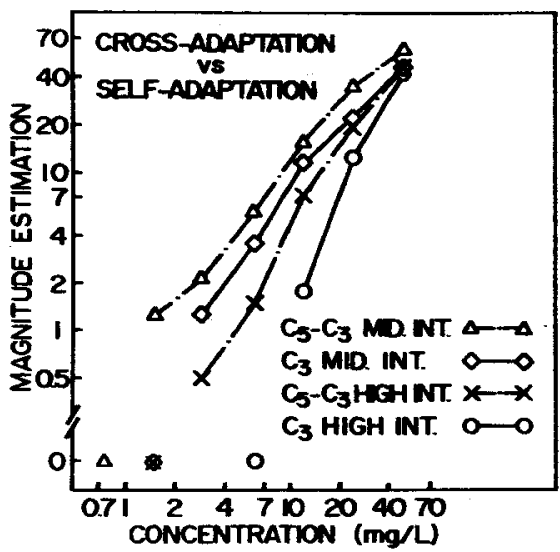

Fig. 7. Functions obthined under two conditions of crossadaptation of propanol by pentanol $\left(C_{5}-C_{3}\right)$ and the comparable conditions of self-adaptation for propanol $\left(c_{3}\right)$.

probably fail only for pairs whose chemical or physical dissimilarity produces larger psychophysical differences than those seen between propanol and pentanol. However, if the relation holds for both similar and dissimilar pairs, it would then be possible to predict the relative adapting effects of concentrations of any two odorants simply from their relative subjective intensities.

The effect of adapting duration on the psychophysical function turmed out to be smaller than expected. Perhaps the effect would have appeared larger if exposures of only one or two breaths had been used. But for durations of at least three breaths and for the range of concentrations studied here, it would obviously take a very long exposure to an adapting stimulus to produce an effect of the same magnitude as that produced by a moderate increase in adapting intensity. Because the effect of duration was so small, it is not yet clear whether or not adapting duration and adapting intensity have the same effect on the form of the psychophysical function. The data for propanol sugzest that an increase in adapting duration may increase the steepness of the lower part of the functions but leave the upper part relatively unaffected. An increase in adapting intensity, on the other hand, seems to cause a more general steepening of the whole function.

There was considerable irregularity in the shapes of the adaptation functions. At the low concentrations, some of the functions were straight and others were concave downward or concave upward. This absence of uniformity may have been due to differences in breathing patterns that alone can change the intensity of an otherwise well-controlled olfactory stimulus. For example, upward concavity 
may indicate that some $O$ s made deeper inhlations of weak stimuli in order to obtain a clearer senation.

A generalized form of the poychophysical power $\operatorname{law}, \psi=\mathbf{k}\left(\varphi-\varphi_{0}\right)^{\beta}$, where $\varphi_{0}$ approximates the absolute threchold, hos proved quite useful to describe the effects of adaptation in vision (Stevens a Stovens, 1963) and taste (Mclinmey, 1960). This equation provided $m$ ercellent description of some, but not sil, of the present results. Some of these remilts conld sloo be well described by a biveguented function that consisted of two strnifhtline sezments (ise., two power functions) with different slopes (exponents) in log tog coordinates. This bieczencented function is similar to those found under various conditions of inhibition (ef., contrast, glare, and moding) in vivion and audition (Stevens, 1966; Stevens \&uirao, 1967). Only further experimentation, with perhaps more attention to the control of breathing, wil tell if one of these two formulations can provide an adequate description of olfactory adaptation.

The results of Experiment 2 show that self-adaptation and cross-adaptation are similar and that a cross-adapting stimulus of a specified subjective intensity acts very much like a self-adapting stimulus of lower intensity. In some cases, a cross-adapting stimulus may hrve the additional effect of changing the perceived quality of the test stimulus, but this possibility was not explored here.

The asymmetry between the crossadapting effects of propanol and pentand has been noted by previous investigators for other pairs of odorants (cf. Moncrieff, 1956; Engen, 1963; Engen \& Bosack, 1969; Corbit, 1969). In some cases, it has taken the extreme form that Odorant A reduced the stimulating effectiveness of Odorant B but Odorant B enhanced the effectiveness of Odorant $A$ (Corbit, 1969; Engen \& Bosack, 1969). Such tects must be carefully considered in any attempt to rehte the similarity of the qualities of two odorants to their mutual crowadapting effectiveness. A judgment of simitarity is typically expected to reflect how mech two colorants hwe in common, and thereby specifies a symmetrical rehtionhip. This symmetry contrasts sharply with the asymmetry of crosedaptation and illustrates that the two procedures at esentially different questions.

\section{REFERENCDS}

CAIN, W. S. Odor intentity: Difierenoes in the exponent of the psychophysical function. Perception \& Psyctophysics, 1969, 6, 349-354. CHEXSIAN, G. H, a MAYNE, S. The infinence of adaptation on abwolute threchold measurements of olfactory stimuli. Quarterly Joumal of Experimental Psychology, 1953, S, 22-30.

CHEESM IAN, G. H., TOWNSEND, M. I. Further experiments on the olfactory thresholis of pure chemical subetances, uxing the "sniffibottie method." Quarterly Joumal of Experimentul Psychalosy, 1956, 8, 8-14.

CORBIT, T. E. Facilitation of olfactory siznal detection by cross-edeptation. Unpubithed doctomel disertation, Brom University, 1969.

EKMAN, G, BERGLUND, B., BERGLUND, U. a LNDVALL, T. Perceived intensity of odor s. a function of time of daptrition. Scandingrien Joumal of Pychology, 1967, 8, 177-186.

ENGEN, T. Crossedeptution to the alliphatic alcoholk American Joumal of Psycholozy. $1963,76,96-102$

ENGEN, T \& BOSACK. T. N. Facilitation in olfactory detection. Journal of Comparative \& Phy siological Psychology, 1969, 68, 320-326.

ENGEN, T., CAIN, W. S., ROVEE, C. K. Direct scaling of olfaction in the newborn infant and the adult human observer. In $\mathrm{N}$ Tmyolac (Ed), Theories of odors and odor mexarrememt Instanbul: Robert Colloge, 1968. Pp. 271-294.

McBURNEY, D. H. Magnitude estimation of the tere of sodiom chloride after adeptation to sodisur chlodide Jound of Expeximental Puscholosy, 1966, 72, 869-873.

MONCRIEFF, R. W. Ofinctory deptation and odour treseses Jomrnal of Physiology, 1956, 133, 301-316.

MONCRTEFF, R. W. Olfmetory daptation and odor-intensity. American Joumel of Prychalog, 1957, 70, 1-20

SchUTZ, H. G., LAYMON, R. S. Ineatiotion of olfactory adaptations. Aperiom Pryclologit, 1959, 14, 429. (Abwent)

SCTUTZ, H. G, OVEREDC, R C a LAYMON, R. S. Relutiondip between finno and physico-chemical properties of conpoends Final Repart, October 1958, Batelle Memorial Institute, Contrect Na. DA-19-129Q4-1141, Qantermader Food an Continer Inetithte for the Armed Forces.

STEVENS, J. C, \& STEVENS, S. S. Bu htwees function: Effect of adpotation Joumb of the Optical Society of Americe, 1963, 53, 375-385.

STEVENS, S. S. Power-eroup trengformations under ghre, moding and recruitneent Joumal of the Acontical Society of Americe, 1966, 39, $725-735$.

STEVENS, S. S., \& GUIRAO, M. Loudnoss functions under intibition. Perception \& Psychophycios, 1967, 2, 459-465.

STUIVER, M. Biophydics of the serse of mudt S-Givenhore (Netherimeds): Excelvior, 1958 WOODROW, H RARPMAN, B, A new olfactometric tochmique and some realls. Joumal of Experimental Prychology, 1917, 2, $431-447$.

WRIGHT, R. H. The science of smell Londoa: Allen \& Unvin, 1964.

\section{NOTES}

1. This report is based on a doctorel dissertation submitted to the Psycholosy Department at Brown Univerity. The investiention was sopported by Grant GB-724 from the National Science Foundation to Tryes Engen and by a PHS predoctoral fellowhip. I wish to thank Professor Engen for his constint guidance and support.

2. Address: John B. Pience Foundation Laborntory, 290 Congress Avenue, New Hiven, Connecticut 06519.

(Accepted for publication Juby 28, 1969) 